\title{
¿ERA LA UNIÓN SOVIÉTICA SOCIALISTA? UNA CRÍTICA A LOS CRÍTICOS DE LA URSS
}

\author{
Juan Miguel Valdera Gil \\ Universidad de Granada \\ valgil@ugr.es
}

http://dx.doi.org/10.5209/rev_NOMA.2014.v44.n4.49295

\begin{abstract}
Resumen.- Este artículo realizará una crítica a aquellas posiciones marxistas que han puesto en tela de juicio el carácter socialista de la URSS. Comenzaremos por enunciar el error de partida en el que, a nuestro juicio, incurren muchos críticos de la URSS. Esto es, juzgar el socialismo soviético a partir de unos cánones ideales que proceden de los autores clásicos del marxismo-leninismo (Marx, Lenin, Trotsky etc.). En la segunda parte del artículo defenderemos el carácter socialista de la URSS. Nuestra tesis será que, en vez de calificar a la Unión Soviética como una desviación respecto al auténtico socialismo, el sistema soviético pudo mantenerse durante largo tiempo, porque abandono en la práctica ciertas ideas muy arraigadas en la tradición marxista-leninista.
\end{abstract}

Palabras clave.- "Comparación platónica", burocracia, Estado obrero deformado, rectificación ideológica, socialismo en un solo país.

\begin{abstract}
This paper offers a critique to those Marxist approaches which have challenged the socialist's character of the Soviet Union. The paper starts by analysing what I view as a common departure misjudgement position shared by many critics: to look at Soviet socialism through the lenses of Marxist- Leninist classic authors and their ideal canons (Marx, Lenin, Trotsky etc.) In the second part this paper defends the socialist underpinnings of the Soviet Union; instead of framing the Soviet Union as a variation of the authentic socialism, the Soviet system managed to sustain itself for a long time as it abandoned certain ideas well routed in the Marxist-Leninist tradition.
\end{abstract}

Keywords. - "Platonic comparison", bureaucracy, deformed workers' state, ideological correction, socialism in one country.

\section{Introducción. El platonismo como metodología de comparación histórica}

En nuestra investigación doctoral abordábamos el estudio de los fundamentos del sistema soviético de estratificación social durante el periodo estalinista. El trabajo constaba de una introducción y tres partes diferenciadas. En el primer bloque se analizaban los fundamentos socio-económicos y político-institucionales- y se trataban cuestiones como la política económica soviética en los años veinte y treinta, la transformación del sistema de ocupaciones o los determinantes institucionales (tipos de propiedad, reparto salarial, distribución de bienes como la vivienda etc.). La segunda parte tenía por título Fundamentos simbólico-legitimadores: el papel de la ideología. Mediante el análisis socio-discursivo de materiales en su versión original rusa, pretendíamos exponer la ideología oficial soviética, poniendo al descubierto las profundas imbricaciones entre los aspectos simbólicolegitimadores y algunas realidades del sistema de estratificación. Respecto a la metodología nos decantamos por un enfoque empírico. En la primera parte usamos datos cuantitativos de carácter secundario; en la segunda una aproximación cualitativa basada en el análisis sociológico del sistema de discursos (Conde, 2009)

Y sin embargo había otra cuestión más "filosófica" que nos parecía importante esclarecer y a la que dedicamos un capítulo en la parte final de la investigación. Allí nos preguntábamos retóricamente, ¿Era el sistema soviético socialista? Para los críticos "liberales" defensores del orden capitalista, la URSS era inequívocamente socialista, porque identifican la dictadura, la represión, la ineficiencia económica, o la pobreza con el socialismo. En cambio 
los críticos de "izquierdas", muy conscientes de las limitaciones reales del sistema soviético, lo ponían en duda. Para ellos el socialismo era otra cosa. Trotsky (2001a) acuñó la expresión de Estado obrero con deformaciones burocráticas; Wright (1994) habla de estatalismo o socialismo estatal burocrático; Buzgalin y Kolganov (2003) emplean el término de socialismo mutante; Cliff (2000) y más recientemente Zdorov (2006), prefieren capitalismo de Estado.

Este artículo tiene como objetivo realizar una crítica constructiva a los autores que, desde posiciones marxistas o neo-marxistas, ponen en cuestión el carácter socialista de la URSS ${ }^{1}$. Sostenemos que detrás de los calificativos estatal, burocrático, mutante o deformado anida la visión de una Unión Soviética que se aleja del camino del verdadero socialismo. Ahora bien, la deformación, aberración o desviación implica la presencia de un patrón o canon que se preste a la comparación. Daremos un par de ejemplos. Primero: un diagnóstico de cáncer supone una mutación de células sanas, que si no se toman medidas, acaba por destruir toda posibilidad de vida. En este caso las células sanas del cuerpo nos sirven para comparar y dictaminar que se ha producido el cáncer. Segundo: para desviarse de un camino, el trazado de la vía debe estar construido o al menos señalado en un mapa. En caso contrario, más que andar por un camino, estaríamos trazándolo según la máxima del poeta español Antonio Machado: "caminante no hay camino, se hace camino al andar". Entonces, ¿qué modelo o patrón toman los críticos de la URSS para elaborar su dictamen? La comparación con proyectos socialistas implantados es complicada. Hasta 1917 la Comuna de París era uno de los pocos movimientos que servían de inspiración. Pero la Comuna fue una experiencia local de corto recorrido. La mayoría de las veces los autores marxistas y neomarxistas siguen un enfoque, que podríamos denominar platónico, en su crítica a la Unión Soviética. Platón defendía (Popper, 2006: 40) una realidad formada por objetos sensibles. La realidad material es una copia de formas puras que únicamente existen en el mundo de las ideas. Los objetos sensibles, entre ellos los sistemas político-institucionales, están sujetos a corrupción. Pasa el tiempo, y los objetos materiales van degenerando y pierden su parecido con las formas puras. La forma perfecta de gobierno, la timocracia, se deforma y pasa por sucesivos estadios a cada cual más decadente: oligarquía, democracia y tiranía. A pesar de su profesión materialista, los críticos de la URSS siguen un método similar al platónico. Las ideas sobre el Estado y la burocracia que emanan de la tradición marxista (las formas puras) son utilizadas para cuestionar la naturaleza socialista de la URSS (el objeto sensible o corrompido). Veamos en líneas generales en qué consiste ese canon tradicional.

\section{El Estado y la burocracia en la tradición marxista: Marx, Lenin, Trotsky}

Empezaremos este epígrafe con un párrafo de Marx, extraído del 18 Brumario de Luis Bonaparte. En él Marx sintetiza de forma clara y concisa su visión del Estado.

[..] Donde el Estado enmaraña, controla, regula, vigila y tutela a la sociedad civil, desde sus manifestaciones de vida más vastas hasta sus movimientos más insignificantes, desde su forma de vida más generales hasta la existencia privada de los individuos; donde ese cuerpo parasitario adquiere, gracias a la extraordinaria centralización, una ubicuidad, una omnisciencia, una capacidad acelerada de movimientos y una elasticidad que solo encuentra analogía en la dependencia desvalida, en la informidad distraída del auténtico cuerpo social. (Marx, 2003: 88)

Karl Marx es un antiestatalista convencido, un demócrata que engarza, en cierto modo, con los liberales y anarquistas más radicales. El Estado se presenta como una entidad ajena, un parasito que se adhiere al auténtico cuerpo social, la sociedad civil, extrayendo de ella su alimento. Como excrecencia que es, el Estado no cumple ninguna función positiva

\footnotetext{
${ }^{1}$ Vamos a excluir de nuestra exposición las teorías del "capitalismo de Estado", porque su crítica bien merece un trabajo aparte.
} 
(enmaraña, vigila, tutela). Sirve o bien a los intereses de la clase dominante, o llegado el caso, a sus propios intereses, tal y como el autor alemán trató de demostrar en su estudio de Napoleón III en Francia. El Estado ejerce su dominación por medio de la burocracia. Cuerpo formado por los supremos gobernantes y todos sus secuaces en la administración, vive rodeada de privilegios y prebendas. La revolución proletaria no solo expropiará a la burguesía, sino que destruirá también a su representante estatal, la burocracia. El viejo aparato estatal será sustituido por uno de nuevo tipo, bajo control obrero, tal y como hizo la Comuna de Paris durante la Revolución de 1870:

He aquí su verdadero secreto: la comuna era esencialmente, un gobierno de la clase obrera, fruto de la clase productora contra la clase apropiadora, la forma política al fin descubierta para llevar a cabo dentro de ella la emancipación económica del trabajo [...] Por tanto la Comuna había de servir de palanca para extirpar los cimientos, los cimientos económicos sobre los que descansa la existencia de las clases, y por consiguiente, la dominación de clases. Emancipado el trabajo, todo hombre se convierte en trabajador, y el trabajo productivo deja de ser atributo de una clase. (Marx, 1980:67)

¿Pero en qué consistía exactamente el nuevo gobierno? La Comuna es la representante de los obreros, una corporación del trabajo. La Comuna no es un organismo parlamentario, sino que tiene funciones ejecutivas y legislativas a la vez. Por ello, la policía y el ejército son puestos inmediatamente a las órdenes del gobierno comunal, al igual que todos los funcionarios y cargos públicos de la administración, que comienzan a cobrar salarios de obreros. Los funcionarios judiciales no se libran de tal distinción; magistrados y jueces han de ser electivos, revocables y responsables. Se decretó también la separación entre Iglesia y Estado. La educación se expandió con la apertura de nuevos centros. El sistema comunal debía extenderse por toda Francia, formándose en todas las provincias pueblos y aldeas órganos similares. El ejército sería reemplazado por milicias populares con un tiempo de servicio corto. La coordinación entre todos los entes comunales se haría mediante órganos electivos de orden ascendente. Las comunas rurales administrarían los asuntos colectivos en asambleas provinciales (distritos), y estas a su vez enviarían delegados a una Asamblea Nacional en Paris. Todos los delegados serían revocables en cualquier momento y estarían ligados a sus electores por mandato imperativo. El rasgo más sobresaliente de la Comuna fue la eliminación de la burocracia permanente y su sustitución por la gestión directa de los obreros.

Las tesis que Lenin (1917) despliega en El Estado y la Revolución son similares a las de Marx. Según Lenin el avance de la democracia burguesa acrecienta la unidad del proletariado y facilita su ascenso como clase dirigente. El desarrollo de la democracia capitalista abre nuevos caminos para destruir el Estado burgués.

Da la posibilidad de destruir, de hacer añicos, de barrer de la faz de la tierra la máquina del Estado burgués, incluso la del Estado burgués republicano, el ejército permanente, la policía y la burocracia, y de sustituirlo por un máquina más democrática, pero todavía estatal, bajo la forma de masas obreras armadas, como paso hacia la participación de todo el pueblo en las milicias. (Lenin, 1997: 98)

La alfabetización de las grandes masas, la concentración de los medios de producción, la disciplina de trabajo engendrada por el moderno modo de producción capitalista, permite que todos los explotados se encuentren en disposición de intervenir en la dirección del Estado. La administración burocrática, nos dirá Lenin, es un asunto que el capitalismo ha simplificado hasta extremos desconocidos (Lenin, 1997: 99). Leer, escribir y realizar operaciones matemáticas sencillas es todo lo que se necesita para que el proletariado ejerza la contabilidad y el control sobre la producción/distribución. Los especialistas técnicos y científicos trabajarán para el nuevo gobierno obrero tal y como trabajan ahora para los capitalistas. El Estado obrero que gestiona los asuntos económicos y políticos con ayuda de 
los soviets, no es propiamente un Estado, sino más bien un Estado que comienza a extinguirse. Como la administración ha dejado de ser un trabajo de unos pocos para ser labor de toda la sociedad, pierde su carácter de mecanismo dominador, porque a su través no puede obtenerse privilegio alguno. Entonces se abrirán las puertas de par en par del comunismo, de la desaparición total de la opresión y la dominación. 


\begin{abstract}
Weber
1. Cuando el Parlamento es simplemente una asamblea que produce discursos, el resultado es una dominación burocrática incontrolada, que sirve a los intereses de los capitalistas y produce un liderazgo político ineficaz e irresponsable
\end{abstract}

2. Las burocracias son, sin embargo, necesarias e inevitables, dadas las condiciones de la tecnología y la producción modernas, así como la escala masiva del Estado moderno

\section{Lenin}

1. El Parlamento no es más que un lugar de charlatanería, los centros reales de poder estatal se localizan en la burocracia controlada por la clase capitalista y al servicio de sus intereses
3. Dado que la burocracia no puede ser eliminada, el problema reside en crear garantías que impidan que los burócratas se salgan de su sitio y controlen la dirección política de la burocracia
2. La burocracia no es un imperativo exigido por la moderna tecnología y administración de masas, sino un imperativo específicamente político de la estabilidad del capitalismo y la dominación de la burguesía

\section{En una sociedad capitalista es} inevitable que las instituciones representativas sean meros centros de charlatanería diseñados para burlar el pueblo; nada puede impedir que en las sociedades capitalistas avanzadas el centro del poder real sea la burocracia

4. Es necesario por tanto poner a punto instituciones que sean capaces de crear un liderazgo político responsable y competente que dirija dicha supervisión
4. Si queremos establecer el socialismo, hemos de crear instituciones que hagan posible que la clase obrera se organice como clase dominante y que hagan de las masas participantes un sujeto revolucionario dotado de conciencia de clase y agudeza política en la administración estatal
5. Esto sólo puede lograrse mediante la destrucción del Parlamento y la burocracia y su remplazo por una dictadura del proletariado organizada en asambleas obreras y una administración soviética

Fuente. Wright (1983: 200)

En lo concerniente a Trotsky (2001a:106) el autor describe la degeneración del partido como raíz de la burocratización del Estado. La primera causa de putrefacción hay que buscarla en la concentración de poder en el Partido, y sobre todo en sus instancias superiores. La prohibición de los partidos de oposición había limitado la autonomía de los soviets como órganos de expresión de los trabajadores. Por otro lado, la proscripción de las facciones en el seno del Partido, trasladó a su estructura interna el estado de excepción que imperaba en el resto de la sociedad. La libertad de crítica y la confrontación de ideas se vieron subordinadas al Comité Central y al cada vez más poderoso Buró Político. En realidad, aunque Trotsky no se sirve de estas palabras, el círculo del poder se iba estrechando. El Partido se arrogó la representación de la sociedad, el Comité Central la del Partido, el Buró Político la del Comité Central y Stalin la de todos ellos (Trotsky, 2001a:113). Hay que sumar que los órganos del Partido empezaban a confundirse cada vez más con los del Estado. La tendencia al arribismo descollaba, por cuanto el Partido se había convertido en la única plataforma de poder real en el país. La muerte de Lenin marcó otro hito en el proceso de degeneración. Stalin jugó sus cartas sabiamente. Abrió las puertas a través del conocido como "Alistamiento Lenin". Una masa de nuevos militantes se afilió a la organización. Muchos se convirtieron en leales burócratas fieles a su jefe, el secretario general. Los viejos 
bolcheviques, núcleo de la organización partidaria y que habían participado en la Revolución, quedaron en minoría frente a esta masa informe y acrítica (Trotsky, 2001a:109).

\title{
3. Burocracia y modernización (socialista)
}

Trotsky vincula la burocratización al aislamiento de la Revolución. En realidad Trotsky no se despega en demasía de las tesis sobre el poder, el Estado y la burocracia de Marx y Lenin. Si bien admite que el Estado tiene una función policial en condiciones de desigualdad y atraso económico, la implantación socialista en un país económica y culturalmente avanzado cierra la puerta a la burocratización. Es cierto que Trotsky acierta a contemplar al Estado como algo más que una superestructura parasitaria. Con su metáfora del gendarme que cuida las puertas del almacén y reparte entre los miembros de la sociedad su escaso contenido, reconoce tácitamente una función reguladora necesaria. Su experiencia militarorganizativa durante la época del comunismo de guerra, así como haber contemplado el ascenso al poder de Stalin, habrían influido en una mayor comprensión del rol de la burocracia. Lenin también se percató de los derroteros que estaba siguiendo el Estado Soviético, aunque su muerte le impidió una reflexión teórica más profunda sobre los acontecimientos.

Los planteamientos tradicionales de raigambre marxista, con los que introducíamos este apartado, no dan debida cuenta de la naturaleza social del régimen soviético. Esclarecedoras a este respecto las impresiones de Entrena:

\begin{abstract}
Sin embargo, lo cierto es que la raíz de los problemas proviene de las debilidades y lagunas de su pensamiento [se refiere a Marx; nota del autor], cuyo economicismo, consideración del poder como algo extraño a la sociedad y orientación prioritaria a subvertir el orden social capitalista repercutieron en que el autor de El Capital no se percatara de la tendencia a la cada vez mayor complejización burocrática de dicho orden y de la función que en este y en cualquier sistema social cumple la normatividad social, entendida, aquí, en un sentido amplio, como un entramado de regulaciones jurídica-políticas, económicas o estrictamente sociales, explícitas o implícitas, formales o informales .(Entrena, 2001: 89)
\end{abstract}

Marx había cantado las alabanzas del sistema capitalista (Marx y Engels, 1987: 44-47). La elevación de las fuerzas productivas, el desarrollo técnico-científico, la secularización de la vida social, en definitiva el dominio de la civilización burguesa y de sus estructuras socioeconómicas, eran todos ingredientes fundamentales para marchar hacia el comunismo. Pero el democratismo recalcitrante de Marx, su reacción ante la apologética defensa del Estado Prusiano de Hegel, le impidieron ver que la imponente máquina burocrática no era un fenómeno ajeno o externo al capitalismo, sino un desarrollo interno del mismo. Sus tan anheladas conquistas de la civilización burguesa incluyen, a la sazón, la racionalización objetiva de las técnicas y de la organización social tanto del Estado como de las empresas capitalistas y por extensión, el crecimiento cuantitativo de la burocracia.

Paul du Gay (2012) en un trabajo que lleva por título En elogio de la burocracia, mantiene una tesis parecida. Du Gay carga contra los críticos premodernos (Maclntyre) y posmodernos (Bauman) de la burocracia. Dichos autores no se percatan de que los rasgos negativos que tanto critican (despersonalización, deshumanización), son desarrollos internos del Estado moderno, que sirven para evitar la corrupción, el nepotismo y la influencia del status en la conformación de las políticas públicas. La tendencia a "despersonalizar" y "deshumanizar" el vínculo entre sujeto y burocracia, es el único medio efectivo descubierto por ahora, para defender la idea de ciudadanía. Y es que basar la administración en las relaciones personales y de cercanía, es también conceder más poder a las personas de alto estatus y capacidad económica. Por otro lado la rutinización e inflexibilidad de la que tanto se quejan los gurús de la nueva gestión empresarial, ayuda a dotar a los procedimientos administrativos de previsibilidad, y garantizar los controles que el legislador, que representa la soberanía popular, debe tener sobre el gasto del dinero público. Compartimos el punto de 
vista de du Gay al reivindicar a Max Weber, como el sociólogo que mejor comprendió la ligazón entre modernización y burocratización:

\begin{abstract}
El desarrollo de las formas "modernas" de asociaciones en toda clase de terrenos (Estado, iglesia, ejército, partido, explotación económica, asociación de interesados, uniones fundaciones y cualesquiera otras que pudieran citarse) coincide totalmente con el desarrollo e incremento creciente de la administración burocrática: su aparición es, por ejemplo, el germen del Estado moderno occidental. A pesar de todos los ejemplos en contrario, sean estos de representaciones colegiadas de interesados, comités parlamentarios, dictaduras de "consejos", funcionarios honorarios o jueces no profesionales ( y sobre todo, a pesar de los denuestos contra la "santa burocracia") no debe uno dejarse engañar y perder de vista que todo el trabajo continuado, se realiza por funcionarios en sus oficinas. Toda nuestra vida cotidiana está tejida desde dentro de ese marco. Pues si la administración burocrática es en general -caeteris paribus- la más racional desde el punto de vista técnico-formal, hoy es, además sencillamente inseparable de las necesidades de las masas (personales o materiales). Se tiene que elegir entre la burocratización y el diletantismo de la administración; y el gran instrumento de la superioridad de la administración burocrática es éste: el saber profesional especializado, cuyo carácter imprescindible está condicionado por los caracteres de la economía moderna de la producción de bienes, siendo completamente indiferente que tal producción sea en la forma capitalista o socialista (esta última, de querer alcanzar iguales resultados técnicos, dará lugar a un extraordinario incremento de la burocracia profesional). (Weber, 2002: 178) [Cursivas nuestras].
\end{abstract}

Si en vez de denostar a la sociología burguesa, los bolcheviques le hubieran prestado atención, quizás se habrían percatado de que el peligro de burocratización era inevitable en el camino al socialismo. El Estado moderno o uno como el soviético que aspiraba a serlo, no se maneja con simples reglas aritméticas, la lectura y la escritura. Contémplese la complejidad en la elaboración de un presupuesto, de las reglamentaciones administrativas y jurídicas, de la contabilidad, de la asignación de recursos humanos y de cualquier tarea organizacional actual. Todo eso, repetimos al unísono siguiendo a Weber, no son argucias ideológicas superestructurales inventadas por la burguesía para dominar. Son prerrequisitos funcionales que hacen trabajar a la máquina de una economía moderna, siendo secundario a quién pertenecen los medios de producción (capitalismo versus socialismo).

Y al igual que Weber predijo la expansión de la burocracia soviética, los bolcheviques más concientes podrían haber previsto que el jefe de la oficina (nos referimos a Stalin) acabaría tomando entre sus manos todo el poder, ya que los otros grupos de la sociedad soviética (campesinos, intelligentsia, obreros), solamente podían dejar sentir su influencia por medio de un partido, que ya estaba de hecho, gobernado por la oficina. Deshaciéndose sucesivamente de los otros líderes, y ante la inexistencia de centros alternativos de poder (sindicatos y soviets independientes), el dominio de la burocracia se había completado. Además el poder de la burocracia por la propia naturaleza del Estado socialista tenía que ser mayor y más difícil de doblegar. La burocracia en el moderno estado capitalista se presenta organizada distributivamente ${ }^{2}$. Significa que junto a una burocracia publica más 0 menos solidificada (dependerá de si el Estado en cuestión es de tipo unitario, federal, descentralizado etc.) conviven una pléyade de órganos gestores de las grandes unidades productivas privadas y de otras organizaciones (partidos, sindicatos, organizaciones benéficas). Estos organismos administran la vida social con momentos de cooperación y de conflicto intra e interburocráticos.

\footnotetext{
2 "Las totalidades atributivas son aquellas cuyas partes están referidas las unas a las otras, ya sea simultáneamente, ya sea sucesivamente -las conexiones atributivas no implican inseparabilidad (por ejemplo en el caso de las conexiones sinecoides o indestructibilidad-; las totalidades distributivas son aquellas cuyas partes se muestran independientes las unas de las otras en el momento de su participación en el todo. Cuadrado, respecto a las figuras cuadradas es una totalidad distributiva (mientras que cuadrado, respecto de los dos triángulos constituidos por una de sus diagonales, es una totalidad atributiva".(García, 2000: 51)
} 
En la URSS, en la práctica, la burocracia se constituyó como una totalidad atributiva. En primer lugar, el monopolismo socialista de la estructura productiva y la nacionalización de los grandes medios de producción, defendida por todos los teóricos bolcheviques, desde Lenin a Preobrazhenky, supone una tendencia a la eliminación de los órganos de gestión independientes. A mediados de los años treinta toda la economía estaba integrada en el complejo socialista bien en forma de propiedad estatal (de todo el pueblo), bien en forma de cooperativas koljosianas. El plan, de obligado cumplimiento, unía a todas las unidades productivas del país, como si de una única empresa se tratara.

Curiosamente, las críticas marxistas (Trotsky, Cliff) y neo-marxistas (Wright, Zdorov, Buzgalin) que minusvaloran el carácter socialista de la URSS reproducen los mismos esquemas reduccionistas que Marx y Lenin aplicaron al Estado y la burocracia. En vez de observar el proyecto soviético a modo de aberración por su estatalismo o burocratismo, nosotros defendemos que fue una rectificación, por la vía de los hechos, de concepciones erróneas muy arraigadas en la tradición marxista-leninista. Hablamos de rectificación por la vía de los hechos, porque ni Stalin ni otros dirigentes soviéticos aceptaron nunca que se estuvieran apartando lo más mínimo de la doctrina oficial. En la Unión Soviética todos los dirigentes desde Stalin hasta Gorbachov, pasando por Trotsky o Bujarin, han declarado siempre ser leales seguidores del marxismo-leninismo a pesar de haber defendido distintas políticas ${ }^{3}$. Ningún dirigente soviético que quisiera seguir siendo relevante cometió el error de admitir que alguno de sus planteamientos se alejaba o contradecía las doctrinas de Marx y Lenin.

Y sin embargo, opinamos que la Unión Soviética difícilmente habría perdurado 70 años si hubieran aplicado con sinceridad el lema un Estado que empieza a extinguirse. Stalin tomó nota de la derrota de la Comuna de París y adoptó en lo referente a la burocracia y el Estado, un punto de vista más cercano a Weber, que a Marx y Lenin. Que el proyecto político estalinista rectificara ideológicamente presupuestos del marxismo-leninismo en su camino de consolidación institucional, no debe entenderse en un sentido teleológico. La institucionalización bien podía haber discurrido por terceras sendas. Con actores, escenario internacional o circunstancias históricas diferentes, la rectificación ideológica habría arrojado probablemente otro resultado. ¿Pero en qué consistió exactamente esa rectificación de la que hablamos? Veámoslo.

\section{La adaptación de las ideas de Marx al contexto ruso. De la posibilidad de revolución socialista}

La teoría del Imperialismo y del capitalismo decadente explica la posibilidad del triunfo del socialismo en Rusia. Lenin (2002) y Trotsky (2001b) modificaron de manera sustancial el papel del capitalismo en el desarrollo de los países atrasados. Influenciados por Hilferding, creyeron que el capitalismo estaba en una nueva fase monopolística, en la cual pierde su función civilizadora. La burguesía colonial impulsa la rapiña en los países colonizados, no su desarrollo.

A diferencia de Marx, los bolcheviques plantearan que la revolución podría comenzar en un país atrasado como Rusia. Es más, el propio atraso impediría a la burguesía cumplir con su tarea progresista. El proletariado en alianza con el campesinado pasa a primera línea de combate y asume la dirección del movimiento revolucionario. La revolución tiene entonces una doble cara. Se arroga cometidos burgueses en sus primeras fases (liquidación del feudalismo, impulso a las fuerzas productivas), pero no se detiene ahí. Guiada por una

\footnotetext{
3 De este hecho se deducen dos consecuencias: 1) el marxismo-leninismo no es un libro de instrucciones donde encontrar soluciones a todos los problemas políticos prácticos; 2) desde un punto de vista weberiano, la apelación al marxismo-leninismo actuaba como fuente de legitimidad tradicional para la dominación en la URSS.
} 
dirección proletaria se dispone a marchar de inmediato por la vía del socialismo. ¿Cómo es posible construir el socialismo sin unas estructuras capitalistas previas?

En este punto los heterodoxos Lenin y Trotsky dirigen su atención a Marx, a los factores exógenos. Garantizar el triunfo de la revolución no atañe en exclusiva a los oprimidos de Rusia. La toma del poder de los obreros en los países capitalistas avanzados (Francia, Gran Bretaña, Alemania) favorecería la federalización de los nuevos Estados socialistas en un ente supranacional y resolvería el problema del atraso.

\section{El nuevo rumbo de Stalin o la rectificación sin ruptura oficial con el marxismo- leninismo}

Lenin era, antes que nada, un internacionalista convencido. Contempla los sucesos de 1917 como un episodio de una serie de revoluciones, la antesala de un socialismo a escala planetaria. Tenemos dos buenos ejemplos en las primeras constituciones soviéticas. El artículo tres del texto de 1918 declara que el nuevo poder se orientará a la supresión de cualquier tipo de explotación, a la eliminación de la sociedad en clases, al aplastamiento implacable de los explotadores, al establecimiento de la organización socialista de la sociedad y a "la victoria del socialismo en todos los países" (Kukushkin y Chistiakov, 1987: 241). La primera Constitución Federal de 1924 se inicia con una declaración de intenciones. Tres son los motivos que se esgrimen. El primero: la destrucción y desorganización material durante la guerra civil aconsejaban que las repúblicas soviéticas unieran fuerzas para restablecer y potenciar la economía socialista. El segundo: ante las nuevas amenazas provenientes del mundo capitalista, plantear batalla en un frente único. La última causa es de carácter ideológico. El Estado soviético es internacionalista y aspira a reunir a todas las repúblicas en una única familia socialista. "Servirá [el Estado soviético] como fiel baluarte contra el capitalismo mundial y como un decisivo paso en el camino de la unión de todos los trabajadores en la República Socialista Soviética Mundial' (Kukushkin y Chistiakov, 1987: 266).

Stalin encauzará ideológicamente el proyecto soviético hacia una revolución nacional, el "socialismo en un solo país". Sus planes y proyectos vuelven a situar a Rusia y otras repúblicas de la URSS en el centro de la historia. Conforme a la nueva doctrina, todas las alusiones de carácter internacionalista desaparecerán de la Constitución de 1936. Vladislav Zubok (2008) ha bautizado esta variante del socialismo soviético como paradigma revolucionario-imperial. La nueva orientación intentaba conciliar los intereses estratégicos y geopolíticos del Estado soviético, con la lucha contra la opresión, la explotación, el colonialismo y por una sociedad más justa e igualitaria (Zubok, 2008:11; 505-506). En la misma línea Luciano Canfora añade, que a partir de Brest-Litovsk, la política exterior soviética empezará a identificar la batalla por la revolución mundial con el apoyo a la Unión Soviética (Canfora, 2011: 374). La nueva interpretación ideológica del internacionalismo proletario en clave imperial-revolucionaria tendrá consecuencias dentro y fuera de la URSS. En el plano internacional, los proletarios de los países capitalistas debían subordinar sus intereses políticos y sindicales inmediatos a la estrategia de la URSS, faro de la revolución mundial. En el plano interno, los campesinos, obreros e intelligentsia se comprometían a anteponer las necesidades militares y económicas de la Unión Soviética a las suyas propias. El servicio al Estado para el eficaz cumplimiento de los planes quinquenales bajo la consiga "los mandos lo deciden todo" (Figes, 2009: 247) era el único camino hacia la sociedad comunista. John Rawls subraya que las únicas desigualdades justas son las que aumentan las rentas absolutas de los miembros más pobres de una sociedad (Milanovic, 2011: 206). El sostén ideológico de la política económica de Stalin guarda cierto parecido con el argumento de Rawls. Los esfuerzos, sacrificios y carencias de los ciudadanos soviéticos se justifican porque incrementan el poder de la URSS, y el fortalecimiento del Estado soviético es la única garantía de bienestar futuro del pueblo y triunfo de la revolución por el mundo. 
El desplazamiento del proyecto soviético hacia una política defensiva y de expansión imperial tras la II Guerra Mundial, colocó a la Unión Soviética en una doble competición con el bloque capitalista. Por un lado, había que demostrar que a la larga, el sistema soviético funcionaría de forma más eficiente que el capitalismo decadente; que concedería un mayor grado de libertad, riqueza, bienestar y oportunidades a los ciudadanos soviéticos. Las leyes del materialismo histórico aseguraban el triunfo del socialismo en la carrera del bienestar. La URSS era más progresista, estaba un peldaño por encima del capitalismo en la escalera del desarrollo humano. Tomar ventaja en la carrera del bienestar tenía un fin propagandístico. La descolonización abrió enormes posibilidades para la revolución internacional. El proyecto soviético se presentaba como la mejor vía para salir de la pobreza y el atraso. El compromiso de ayuda al tercer mundo y a las democracias populares hermanas imponía no quedarse atrás en la carrera militar. Ningún imperio a lo largo de la historia ha alcanzado importancia global sin un reforzamiento de sus capacidades ofensivas y defensivas. Las investigaciones nucleares y el desarrollo de misiles balísticos, que datan de la época de Stalin, son buena prueba de ello. Las dos carreras, del bienestar y militar, formaban parte en realidad de una única pugna entre dos sistemas antagónicos, y que sin embargo, compartían un fondo común de carácter modernizador:

\begin{abstract}
Estados Unidos también tuvo la suerte de tener un enemigo que representaba el reflejo ideológico, económico y político del capitalismo occidental. Ese enemigo era el resultado de la búsqueda de la modernidad por parte de los europeos. En otras palabras, la Guerra Fría fue una competición entre dos primos muy lejanos, que luchaban por decidir la mejor manera de modernizar y globalizar el mundo, no entre amigos y enemigos de la modernización y la globalización. (Zubok, 2008: 516)
\end{abstract}

Para terminar queremos lanzar una reflexión. A lo largo del artículo hemos remarcado los elementos que Lenin y Trotsky primero, y Stalin después, modificaron en relación a las ideas de Marx: la posibilidad real de revolución en Rusia, el rol del Estado y de la burocracia y el papel del imperio socialista, son todos puntos donde se hace notar un alejamiento respecto al pensador de Tréveris. Sin embargo tampoco querríamos caer en un planteamiento erróneo, que consiste en desconectar por completo a Marx del proyecto soviético. Marx era más que un retrato al que adorar en los desfiles conmemorativos. He aquí algunos ejemplos de continuidad. En Marx los campesinos constituyen una clase del pasado, de un modo de producción en extinción destinados a desaparecer con el empuje de la sociedad burguesa. Con la colectivización forzosa, los soviéticos querían forzar su rápida disminución y traslado a la ciudad. Marx pensaba que la abolición del capitalismo impondría la nacionalización de las grandes propiedades de la burguesía: los soviéticos expropiaron a terratenientes y capitalistas. Marx defendía un periodo de dictadura transitoria ante la previsible resistencia de la burguesía a la implantación del nuevo régimen; los soviéticos tomaron buena nota, y utilizaron la violencia contra los que se oponían al cambio. Marx supeditaba la desaparición de las clases sociales a un crecimiento elevadísimo de las fuerzas productivas; los soviéticos desarrollaron la industria de forma acelerada. Marx compartía con los ilustrados la fe en el conocimiento y la ciencia, auténticas palancas de transformación de la realidad; los soviéticos promovieron una política de prestigio de la ciencia y la técnica.

\title{
6. A modo de conclusión: socialismo genérico y socialismo específico
}

No sólo desde la crítica política se ha cuestionado la naturaleza socialista de la URSS. Historiadores y especialistas han compartido este punto de vista. Por ejemplo, el sociólogo e historiador Ovsey Shkaratan (2009: 51-54) utiliza la expresión de sociedad etatocrática para referirse a la URSS. La etatocracia, supone un modelo donde el Estado asume un papel económico central y el reparto de la riqueza se realiza a través de mecanismos administrativos no mercantiles. La posición del sujeto viene determinada por su relación con el Estado, de la cual se deduce su adscripción legal a un estamento o êtats del sistema de estratificación social. El historiador Moshe Lewin (2006: 475) llega a conclusiones parecidas y bautizará al régimen soviético como absolutismo burocrático. Tanto para Shkaratan como para Lewin el sistema soviético no fue socialista, porque las particularidades 0 
singularidades históricas asociadas a su pasado lo impedían. Lewin (2006: 471) defiende un socialismo donde la propiedad de los medios de producción es de la sociedad y no de la burocracia, un sistema donde la economía sea socializada y la política se democratice.

En nuestra opinión, mezclar la ideología socialista en un sentido genérico con los proyectos específicos que de esta ideología se desprenden puede llevar a equívoco o confusión. Estamos de acuerdo en que todo socialismo aspira a una socialización efectiva de la riqueza y una democratización de la política. ¿Acaso la Unión Soviética no profesaba oficialmente tan altas metas? Sí, pero era una fachada porque la burocracia dominaba la economía y la política, respondería Lewin (2006: 471). He aquí la raíz del problema. No existe una forma unívoca de interpretar qué significa socializar la economía y democratizar la política, ni de cómo conseguirlo.

En 1848 Marx y Engels ya se percataron de la pluralidad a la hora de entender el socialismo. En el último capítulo del Manifiesto Comunista (1987: 66-76) dan cuenta de cinco modelos de socialismo enfrentados al suyo: socialismo reaccionario (dividido a su vez en una rama feudal, otra pequeño-burguesa y una tercera de socialismo alemán), socialismo conservador y socialismo utópico. Y ello sin contar el anarquismo o socialismo libertario que le disputará la hegemonía en el movimiento obrero al marxismo. Además del propio pensamiento de Marx y Engels han surgido tres movimientos o generaciones de izquierda (Bueno, 2003): la socialdemocracia europea, el comunismo soviético y el maoísmo chino. Cada uno de ellos posee su propia concepción de cómo transformar en realidad los ideales o principios genéricos del socialismo. Los tres se han autoproclamado como los auténticos portadores de los valores socialistas y han criticado al resto por su traición, tibieza o burocratización. Desde nuestro punto de vista, el proyecto soviético ha sido una de las posibles modulaciones del movimiento socialista, una vía al socialismo con sus propias peculiaridades culturales, ideológicas e institucionales que fracasó en 1991. Lo que se trata en realidad de dilucidar son los determinantes concretos, históricos e ideológicos por los que los principios genéricos de "socialización de la economía" y "democratización de la política" acabaron por convertirse en un modelo específico de planificación central, sirviendo de germen para la constitución del sistema soviético tal y como lo conocimos. Queremos apuntar, aunque sea de modo esquemático a tres causas históricas.

En primer lugar, señalaremos que el "gran giro" impuesto por Stalin con la colectivización forzosa y la industrialización acelerada a principios de la década de los treinta, respondía a un proyecto de modernización rápida e incruenta, que buscaba modificar radicalmente la estructura de clases existente en la URSS y garantizar la seguridad del país. La Nueva Política Económica (NEP) que combinaba intervención del Estado y mecanismos mercantiles no dio los frutos deseados. A pesar de que permitió la recuperación económica tras la guerra civil, no fue capaz de impulsar una industrialización a ritmo acelerado y reducir el peso del campesinado en la economía. Ante el aislamiento internacional del país y la sensación de indefensión frente a enemigos imaginarios o reales ${ }^{4}$, se optó por un modelo radical de desarrollo basado en la planificación.

\footnotetext{
4 "Estamos yendo a toda marcha por el sendero de la industrialización hacia el socialismo, dejando atrás nuestro retraso ruso de siglos. Nos estamos convirtiendo en un país del metal, un país del automóvil, un país del tractor. Y cuando hayamos sentado a la URSS en un automóvil y al campesino en un tractor, que intenten entonces alcanzarnos los honorables capitalistas, que alardean de su civilización. Veremos entonces qué países pueden considerarse atrasados y cuáles avanzados [...]. Rebajar el ritmo significa quedarse atrás. Y los que se quedan atrás son derrotados. Pero no queremos ser derrotados. ¡No, no lo queremos! La historia de la vieja Rusia, consistió, entre otras cosas, en ser constantemente derrotada a causa de su atraso. La vencieron los khans mongoles, los beys turcos, los señores feudales suecos, los nobles polacos y lituanos, los capitalistas ingleses y franceses, y los barones japoneses. Fue derrotada por todos ellos como consecuencia de su atraso [...]. Marchamos con un atraso de cincuenta o cien años respecto a los países adelantados. En diez
} 
En segundo lugar, hay que referirse al enfrentamiento del proyecto soviético con la socialdemocracia europea y el capitalismo liberal. El proyecto de socialismo defendido por Lenin y Trotsky e institucionalizado a la postre por Stalin, surgió como una escisión en el seno de la socialdemocracia europea. El socialismo soviético anatemizará a los socialdemócratas, a los que acusará de conciliación con la burguesía, reformismo y complicidad con la carnicería de la I Guerra Mundial. Por otro lado, a finales de los años veinte, el capitalismo estaba en franca decadencia. El crack de 1929 confirmaba a los ojos de los soviéticos la podredumbre del sistema burgués. Además los fascismos comenzaban a arrinconar a la democracia liberal en toda Europa. En consecuencia el modelo que los soviéticos estaban construyendo acabó por apartarse tanto de la socialdemocracia, a la que consideraban corrompida, como del capitalismo, al que veían finiquitado (abandono de la NEP).

En tercer lugar y no por ello menos importante, nos encontramos con las singularidades históricas y culturales de la sociedad rusa. Autores como Shkaratan (2009) y Kara-Murza (2008), autor de La civilización soviética, han insistido en ello. La inercia institucional coadyuvó al triunfo del socialismo específico de planificación. El Estado, garante del bien común en la tradición ortodoxa (y también católica), estaba en mejores condiciones de dirigir los cambios frente a unas estructuras capitalistas débiles y poco implantadas. Así, aunque el socialismo soviético se inspiraba en una ideología modernizadora, se construyó sobre el sustrato cultural e institucional de la vieja Rusia. El modelo resultante fue por tanto una mezcla donde convivían nuevas instituciones nacidas en el proceso de modernización, con otras muy arraigadas en la civilización rusa. Pero creemos que este hecho no debe entenderse como una de rémora que imposibilitó la construcción de un régimen genuinamente socialista. Las revoluciones nunca se hacen desde cero. Suponen destruir instituciones del pasado utilizando y reconstruyendo otras. Cualquier régimen revolucionario sea del signo que sea, tendrá siempre que arrastrar para bien o para mal "la carga" de su civilización y de su historia. $Y$ por eso tampoco existen dos modelos de capitalismo exactamente iguales y de forma análoga, cada régimen de socialismo real portaba sus propias particularidades culturales: Cuba no era la Unión Soviética y la Unión Soviética no era China. Terminaremos nuestra exposición con una cita extensa de Aleksandr Zinoviev, filósofo y escritor ruso y gran crítico del sistema soviético, pero también de las reformas neoliberales posteriores. Zinoviev en una entrevista concedida a Antonio Fernández (2015) apunta al problema de las comparaciones, que nosotros hemos denominado platónicas al comienzo del artículo. Después describe los rasgos que hacían de la Unión Soviética una sociedad inequívocamente diferente de los regímenes capitalistas occidentales.

Dicen que el sistema social soviético no fue auténtico comunismo, entonces yo pregunto, ¿cuál fue o es el auténtico? Si se ha dado en algún sitio, imuéstrenlo! Citan a Marx. Vea usted lo que sucede: las palabras de Marx son el comunismo correcto, y todo lo que en realidad ha ocurrido, eso no es correcto. ¿Entonces las palabras las utilizamos para designar cosas reales o al contrario? Desde este punto de vista, el capitalismo es incorrecto. Y el feudalismo también es incorrecto. Todas estas reflexiones están construidas sobre la base de un pensamiento diletante y pequeñoburgués. Actuaremos como debe hacerse en la ciencia. En la URSS posterior a la Revolución se configuró un sistema social que se diferenciaba del sistema social que había en Occidente. Eso es un hecho. Estudiamos este sistema. Cómo lo vamos a llamar, es otra cuestión. En la mayoría de los casos lo llamarían comunismo o socialismo. [...] Fue liquidada la propiedad privada sobre los medios de producción, los cuales fueron socializados y convertidos en propiedad del Estado. Fue liquidada la clase social de propietarios privados (capitalistas, terratenientes, etc.). Fue realizada la colectivización de la agricultura. La gente no podía ni comprar ni vender la tierra, no podía ni comprar ni vender las fábricas. Fue instituido un único sistema de poder y dirección que atravesaba a toda la sociedad. Fue instituido un único

años tenemos que salvar esa distancia. O lo hacemos, o nos aplastan". (Stalin, citado por Service, 2000: 175) 
sistema económico planificado. Fue instituida una ideología estatal única. Todas las personas en este sistema, a diferencia de sociedades como la feudal o la capitalista, se clasifican por otros criterios. Si tomamos como ejemplo una empresa, vemos que no hay dueño, desde el director hasta la limpiadora son todos empleados del Estado, todos son asalariados. Entre ellos se diferencian por otros rasgos: se dividen en jefes y subordinados. Se establece una jerarquía de dirección, digamos que con 10 o 15 niveles. Es decir, esta sociedad tiene su propia estructura, su propio sistema de poder, su propio sistema económico, su propia ideología, su propia estructura de población, sus propios principios de redistribución. Yo describo este sistema, y como lo llamen después es un asunto secundario. Destacando el objeto de estudio mediante el sistema anteriormente utilizado, después realizo un análisis sistemático del mismo con los métodos de la ciencia.

\section{Referencias bibliográficas}

Bueno, G. (2003), El mito de la izquierda, Ediciones B, Barcelona.

Buzgalin, A.V. \& Kolganov, A.I (2003), Stalin i raspad SSSR, URSS, Moskva.

Canfora, L. (2008), "De Stalin a Gorbachov: cómo acaba un imperio", En D. Losurdo. Stalin: historia y crítica de una leyenda negra, El Viejo Topo, Madrid, pp.365-382.

Cliff, T. (2000), Capitalismo de Estado en la URSS, Ediciones En lucha, Barcelona.

Conde, F. (2009), Análisis sociológico del sistema de discursos, Centro de Investigaciones Sociológicas, Madrid.

Du Gay, P. (2012), En elogio de la burocracia, Siglo XXI, Madrid.

Entrena, F. (2001), Modernidad y cambio social, Trotta, Madrid.

Fernández, A. (2015, 8 de febrero), Entrevista a Aleksandr Zinoviev [publicado en memoria de Zinoviev fallecido en 2006], Asociación de amigos del arte y la cultura de Valladolid.

Descargado de:

http://www.ddooss.org/articulos/entrevistas/Alexnadr_Alexandrovich_Zinoviev.htm

Figes, O. (2009), Los que susurran: la represión en la Rusia de Stalin, Edhasa, Barcelona.

García, P. (2000), Diccionario Filosófico, Pentalfa, Oviedo.

Kara-Murza, S. (2008), Sovetskaya tsivilizatsiya, Algoritm, Moskva.

Kukushkin, YU. S. \& Chistyakov, O.I. (1987), Ocherk istorii Sovetskoy konstitutsii, Polizdat, Moskva.

Lenin, V. (1997), El Estado y la revolución, Fundación Federico Engels, Madrid.

Lenin, V. (2002), El imperialismo: fase superior del capitalismo, Fundación Federico Engels, Madrid.

Lewin, M. (2006), El siglo soviético: ¿Qué sucedió realmente en la Unión Soviética?, Crítica, Barcelona.

Marx, K. (1980), La guerra civil en Francia, Progreso, Moscú.

Marx, K. \& Engels, F. (1987), El manifiesto comunista, Endymion, Madrid.

Marx, K. (2003), El dieciocho brumario de Luis Bonaparte, Alianza, Madrid.

Milanovic, B. (2011), The haves and the have-not: a brief and idiosyncratic history of global inequality, Basic Books, New York.

Popper, K. (2006), La sociedad abierta y sus enemigos, Paidós, Barcelona.

Service, R. (2000), Historia de Rusia en el siglo XX, Crítica, Barcelona.

Shkaratan, O. I. i kollektiv. (2009), Sotsial'no-ekonomicheskoye neravenstvo i ego vosproizvodstvo v sovremennoy Rossii, OLMA media grupp, Moskva.

Trotsky, L. (2001a), La revolución traicionada: ¿qué es y adónde va la URSS? Fundación Federico Engels, Madrid

Trotsky, L. (2001b), La revolución permanente, Fundación Federico Engels, Madrid.

Weber, M. (2002), Economía y sociedad, Fondo de Cultura Económica, Madrid.

Wright, E. O. (1983), Clase, crisis y Estado, Siglo XXI, Madrid.

Wright, E. O. (1994), "Reflexionando una vez más sobre el concepto de estructura de clases", En J. Carabaña \& A. de Francisco (comps.), Teorías contemporáneas de las clases sociales, Madrid, Editorial Pablo Iglesias, pp.17-125.

Zdorov, A. A. (2007), Gosudarstvennyy kapitalizm i modernizatsiya Sovetskogo Soyuza, URSS, Moskva. 
Zubok, V. (2008), Un imperio fallido: la Unión Soviética durante la Guerra Fría, Crítica, Barcelona. 